\title{
Book Review - Buchbesprechung - Livre nouveau
}

R.Tuttle: The Functional and Evolutionary Biology of Primates. Aldine-Atherton, Chicago/New York, 1972. XXII+ 487 pp.

This collection of new studies on primate biology has resulted from a Wenner-Gren symposium at Burg Wartenstein in 1970 which had been organized by the editor. The 19 chapters by different authors deal with a wide variety of primatological interests bearing on evolution. For the first section Szalay has contributed a splendid review of the earliest primates from the paleocene of Europe and North America which have recently become better known through the reexamination of old material and the discovery of new specimens. The demonstration of the surprisingly many specializations in the dentition and other morphological features has led the author to critical comments on probable differences in feeding as well as in locomotor adaptations. The second paleoprimato-logical chapter deals with the hominoids for which Simons and Pilbeam give a brief up-to-date survey, introduced by the frank admission that 'much more effort should be directed toward recovery of new and better material of them. What we have is by no means adequate to interpret their evolution'. Of special interest are naturally the authors' latest conclusions regarding the nature, age and relationship of new discoveries in Egypt, India and East Africa. The 3rd chapter, by Tobias, contains a welcome catalogue of the rapidly growing wealth of early African hominids together with information on their current investigation. Cranial morphology is represented by the next two contributions. With the aid of wide-ranging and interesting comparisons Cartmill discusses his theory that it was not simply arboreal life, but mainly eye-hand coordination which led to the decisive cranial specializations of the early simian primates. Howells explains and exemplifies the value of modern multivariate statistical methods, applied to skull measurements, for indicating the affinities of recent and fossil men. Three further chapters deal with the evolution of the brain of primates. Stephan reviews the latest attempts to evaluate relative brain weight, freed of allometric influence, and to obtain a fuller appreciation of the proportionate size of different cerebral parts through comparative studies on adults without, however, considering the widely different rates of growth of the brain. Radinsky describes a procedure for producing latex endocasts of recent and fossil crania and discusses the type of information which can (and cannot) be gained from such material. The evolution of the hominoid brain and particularly of the brain of the australopithecines is the subject of Holloway's chapter with many daring speculations regarding the relations between brain size and behavior, language, etc., as well as even a proposed model of hominid evolution in general. The 4th and largest section of the book with its 7 chapters on postcranial morphology is specially welcome in view of the comparative rarity of interest as well as of adequate fossil material for such phylogenetic investigation. From his comparative studies of the hominoid wrist Lewis concludes, e. g., that the miocene Dryopithecus africanus had already become adapted to a suspensory arm-swinging locomotion. Many of the profound specializations of the vertebral col-

476 Book Review - Buchbesprechung - Livre nouveau 
umn among primates are ably described in their functional roles by Ankel. The contribution by Wilson is concentrated on tail reduction among macaques with the correlated changes in construction, function and behavior. Tuttle reviews his quantitative findings on the cheiridial muscles of catarrhines and their functional significance. Current results of electromyographic studies on posture and locomotion are presented by Basmajian and shown to have a promising usefulness for analyzing the bone-joint-muscle relationships in primates. In two chapters Oxnard summarizes his multivariate statistical investigation of the shoulder girdle of primates and describes other techniques for elucidating the functional biology of especially skeletal structures. The last section of this rich volume switches to behavior and ecology. Here Beck and Tuttle give an instructive account of the activities of langurs at a waterhole with unobstructed visibility as an example of a very fruitful way to study the terrestrial behavior of arboreal species. In two further chapters Sade and Bernstein respectively deal with longitudinal studies on relatively free-ranging and on caged monkeys, emphasizing the many advantages as well as the limitations of such sociobiological work. The thoughtful discussions of these authors can here no more be briefly reviewed than the final chapter by Cohen entitled 'Aping monkeys with mathematics'. It must suffice to mention that this last essay is a persuasive plea for the use of mathematical models in the analysis of primate evolution, whether concerned with morphology or with behavior.

The volume contains 24 plates of well-reproduced illustrations besides numerous drawings in the text and ends with 31 pages of all the references and a really useful index. There are extremely few and merely minor printer's errors and the entire book has evi dently been prepared with conscientious care. Modern primatological research with its many new view-points and techniques is well represented by the examples in this splen did volume which fully deserves a wide distribution. A. H. Schultz, Zurich 